\title{
Fungicide Sensitivity and Phylogenetic Relationship of Anthracnose Fungi Isolated from Various Fruit Crops in Japan
}

\author{
Wen-Hsin Chung, National Institute for Agro-Environmental Sciences, Tsukuba, Ibaraki 305-8604, Japan (National \\ Chung Hsing University, Taichung 402, Taiwan, ROC); Hideo Ishii and Kumiko Nishimura, National Institute for \\ Agro-Environmental Sciences, Tsukuba, Ibaraki 305-8604, Japan; Masako Fukaya, Akita Fruit Tree Experiment \\ Station, Hiraka, Akita 013-0102, Japan; Kazutaka Yano, Kochi Agricultural Research Center, Nankoku, Kochi 783- \\ 0032, Japan; and Yuji Kajitani, Fukuoka Agricultural Research Center, Chikushino, Fukuoka 818-8549, Japan
}

\begin{abstract}
Chung, W.-H., Ishii, H., Nishimura, K., Fukaya, M., Yano, K., and Kajitani, Y. 2006. Fungicide sensitivity and phylogenetic relationship of anthracnose fungi isolated from various fruit crops in Japan. Plant Dis. 90:506-512.

Anthracnose diseases of fruit crops are mainly caused by Colletotrichum gloeosporioides and $C$. acutatum. In these Colletotrichum species, intra- and interspecific variation in fungicide sensitivity has been reported; however, the relationship between fungicide sensitivity and molecular phylogeny has not been analyzed. Fifty-one isolates from 10 fruit crops, acacia, and tea were tested for their sensitivities to thiophanate-methyl, diethofencarb, and iminoctadine-triacetate, and their internal transcribed spacer (ITS) and 5.8S regions of rDNA were analyzed. C. gloeosporioides isolates were divided into sensitive, less sensitive, intermediate resistant, or resistant to the three fungicides. In contrast, $C$. acutatum isolates were all less sensitive. In molecular phylogenetic analyses, $C$. gloeosporioides isolates fell into the same genetic group, whereas $C$. acutatum isolates were placed into two genetic groups. Although phylogenetic relationship was not closely related to fungicide sensitivity, the isolates of $C$. gloeosporioides most resistant to iminoctadine-triacetate were found in the same phylogenetic subgroup.
\end{abstract}

Additional keywords: $\beta$-tubulin gene, benzimidazole fungicides

Colletotrichum gloeosporioides (Penz.) Penz. \& Sacc. and C. acutatum J.H. Simmonds cause important anthracnose diseases of fruit crops worldwide $(2,12,38,42)$. In Japan, C. gloeosporioides is one of the most common fungi and causes anthracnose on 86 crops, whereas $C$. acutatum causes anthracnose on 18 crops (41). Several fungicides, such as the benzimidazoles, diethofencarb in a mixture with thiophanate-methyl, and iminoctadinetriacetate, have been used effectively to control anthracnose diseases of various fruit crops $(13,18,19,30)$. However, $C$. gloeosporioides isolates that are less sensitive or resistant to these fungicides have been detected $(14,15,18,28,44)$. Similarly, C. acutatum isolates obtained from grapevine, apple, and Japanese pear were less sensitive to benomyl and diethofencarb $(13,15,18,28,33)$. A single-point mutation in the gene encoding the fungicidetargeted protein $\beta$-tubulin has been associated with moderate or high levels of resistance to benzimidazole fungicides in

Corresponding author: Hideo Ishii

E-mail: hideo@niaes.affrc.go.jp

Accepted for publication 20 November 2005.

DOI: 10.1094/PD-90-0506

(C) 2006 The American Phytopathological Society several fungal pathogens $(1,17,18,22,28$, 44,45).

Molecular analysis is a useful tool for studying phylogenetic relationships of filamentous fungi and for relating it to host-specificity, geographical variation, and gene-diversity among intra- and interspecies groups (26). For instance, Freeman (10) used arbitrarily primed polymerase chain reaction (ap-PCR) to analyze Colletotrichum spp. obtained from various fruit crops and found that DNA polymorphisms corresponded to the host and geographic distribution. Similarly, based on the nucleotide sequence of the internal transcribed spacer (ITS) regions of rDNA, species-specific primers were designed and used successfully for identifying $C$. gloeosporioides and $C$. acutatum $(23,24,35,36)$. Further, Freeman and Shabi (12) compared the polymorphism of genomic DNA of Colletotrichum spp. from various hosts and reported that molecular divergence existed among $C$. gloeosporioides and $C$. acutatum. Moreover, the sequence of D2 domain of large-subunit rDNA showed that intra- and interspecies variation existed in Colletotrichum spp. $(9,11,20)$.

To effectively control anthracnose diseases, it is necessary to determine the sensitivity of isolates of the Colletotrichum species causing the disease to fungicides. The objectives of this study were (i) to examine sensitivity of $C$. gloeosporioides and $C$. acutatum isolates obtained from various fruit crops in Japan to the three fungicides, thiophanate-methyl, diethofencarb, and iminoctadine-triacetate using in vitro methods, (ii) to analyze ITS and 5.8S regions to understand the relationships between fungicide sensitivity and molecular phylogeny of the isolates examined, and (iii) to sequence the partial $\beta$-tubulin gene, including the amino acid codons 198 and 200 , which have been reported to be responsible for resistance or lower sensitivity to benzimidazoles of C. gloeosporioides and $C$. acutatum, respectively. Brief results from this work have been reported previously $(14,15,17,44)$.

\section{MATERIALS AND METHODS}

Fungal isolates and fungicides. Fiftyone Colletotrichum isolates obtained from fruit trees (Japanese pear (Pyrus pyrifolia var. culta), grapevine (Vitis spp.), apple (Malus pumila var. domestica), peach (Prunus persica), loquat (Eriobotrya japonica), prune (P. domestica), Japanese plum ( $P$. salicina), Japanese chestnut (Castanea crenata), blueberry (Vaccinium spp.) and akebia (Akebia spp.)), soft fruit (strawberry (Fragaria $\times$ ananassa) $)$, and woody plants (tea (Camellia sinensis), acacia (Acacia spp.)) were used (Table 1). The benzimidazole fungicide thiophanatemethyl (70\% WP), iminoctadine-triacetate (25\% WP), and the $\mathrm{N}$-phenylcarbamate fungicide diethofencarb (25\% WP) were used in the study.

Determination of sensitivity of Colletotrichum isolates to fungicides. Sensitivities of Colletotrichum isolates to thiophanate-methyl, diethofencarb, and iminoctadine-triacetate were tested using mycelial growth assays. Each isolate was cultured on potato dextrose agar (PDA) dishes at $25^{\circ} \mathrm{C}$ for 5 days. Mycelial disks, $4 \mathrm{~mm}$ diameter, were cut from the margins of colonies and transferred onto PDA dishes amended with $0,1,10$, and 100 $\mathrm{mg} /$ liter active ingredient (a.i.) of thiophanate-methyl or diethofencarb, and 0,1 , 10,100 , and $1,000 \mathrm{mg}$ a.i./liter of iminoctadine-triacetate. Diethofencarb and iminoctadine-triacetate were added to PDA after autoclaving, and thiophanate-methyl was added to PDA before autoclaving. After incubation at $25^{\circ} \mathrm{C}$ in the dark for 3 days, the diameter of each colony was 
measured and the $\mathrm{EC}_{50}$ for each fungicide was calculated using log-linear model software kindly supplied by ZEN-NOH (Tokyo).

DNA extraction and PCR amplification. DNA extraction followed the method of Goodwin and Lee (16). From this crude DNA extract, 1 to $2 \mu \mathrm{l}$ was used directly for each PCR amplification.

Identification and assignment of isolates into $C$. gloeosporioides and C. acutatum were performed using the species-specific primers CgInt (24) and CaInt2 (37). For molecular phylogenetic analysis, the ITS1,
5.8S rDNA, and ITS2 regions were amplified using a primer pair of ITS1 and ITS4 (43). Amplifications were done using $20 \mu \mathrm{l}$ of PCR reaction solutions. The PCR reaction mixture contained total DNA, $1.5 \mathrm{mM}$ $\mathrm{MgCl}_{2}, 200 \mu \mathrm{M}$ each dNTP, and 2.5 units of Taq DNA polymerase (Nippon Gene, Toyama, Japan). For an initial amplification, the PCR reaction program followed the procedure of Chung and Tsukiboshi (4). PCR products were run on $1.5 \%$ agarose gels in TAE (Tris-acetate, EDTA) buffers then stained with $0.5 \mu \mathrm{g} / \mathrm{ml}$ ethidium bromide.
Analysis of $\beta$-tubulin gene. The $\beta$ tubulin gene, including the amino acid codons 198 and 200, was amplified by $\mathrm{C}^{\prime}$ and $\mathrm{F}$ primers (1). The PCR reaction mixture and reaction program followed were those reported by Albertini et al. (1). PCR products were first purified by Wizard PCR Preps DNA Purification System (Promega, Madison, WI). Purified PCR products were reacted with BigDye Terminator v3.1 Cycle Sequencing Kit (Applied Biosystems, Foster City, CA) under the following conditions: 25 cycles of $96^{\circ} \mathrm{C}$ for $10 \mathrm{~s}, 50^{\circ} \mathrm{C}$ for $5 \mathrm{~s}, 60^{\circ} \mathrm{C}$ for $4 \mathrm{~min}$.

Table 1. Source of Colletotrichum isolates used in this study and sensitivity to thiophanate-methyl, diethofencarb, and iminoctadine-triacetate

\begin{tabular}{|c|c|c|c|c|c|c|}
\hline \multirow[b]{2}{*}{ Isolate } & \multirow[b]{2}{*}{ Host } & \multirow[b]{2}{*}{ Location } & \multirow[b]{2}{*}{ Species $^{b}$} & \multicolumn{3}{|c|}{ Phenotype $^{a}$} \\
\hline & & & & $\begin{array}{c}\text { Thiophanate- } \\
\text { methyl }\end{array}$ & Diethofencarb & $\begin{array}{c}\text { Iminoctadine- } \\
\text { triacetate }\end{array}$ \\
\hline $\mathrm{GC} 1-1^{\mathrm{c}}$ & Japanese pear & Akita & C. acutatum & LS & LS & LS \\
\hline $\mathrm{GC} 1-2^{\mathrm{c}}$ & Japanese pear & Akita & C. acutatum & LS & LS & LS \\
\hline I5- $1^{\mathrm{d}}$ & Japanese pear & Kochi & C. gloeosporioides & $\mathrm{S}$ & LS & $\mathrm{S}$ \\
\hline I6- $1^{\mathrm{d}}$ & Japanese pear & Kochi & C. gloeosporioides & IR & LS & $\mathrm{S}$ \\
\hline I9- $1^{\mathrm{d}}$ & Japanese pear & Kochi & C. gloeosporioides & $\mathrm{S}$ & LS & $\mathrm{S}$ \\
\hline M14-2 & Japanese pear & Kochi & C. gloeosporioides & IR & LS & $\mathrm{S}$ \\
\hline M19-1 ${ }^{\mathrm{d}}$ & Japanese pear & Kochi & C. gloeosporioides & IR & LS & $\mathrm{S}$ \\
\hline SA02-1-1 & Japanese pear & Saga & C. gloeosporioides & HR & $\mathrm{S}$ & $\mathrm{S}$ \\
\hline SA02-3-2 & Japanese pear & Saga & C. gloeosporioides & $\mathrm{S}$ & LS & HR \\
\hline SA02-5-1 & Japanese pear & Saga & C. gloeosporioides & HR & $\mathrm{S}$ & $\mathrm{S}$ \\
\hline SA02-6-1 & Japanese pear & Saga & C. gloeosporioides & $\mathrm{S}$ & LS & $\mathrm{S}$ \\
\hline SA02-8-1 & Japanese pear & Saga & C. gloeosporioides & HR & $\mathrm{S}$ & $\mathrm{S}$ \\
\hline Nashi-2 & Japanese pear & Aichi & C. gloeosporioides & $\mathrm{S}$ & LS & HR \\
\hline Nashi-10 & Japanese pear & Aichi & C. gloeosporioides & $\mathrm{S}$ & LS & HR \\
\hline B-60 & Grapevine & Akita & C. gloeosporioides & $\mathrm{S}$ & LS & $\mathrm{S}$ \\
\hline $\mathrm{C} 1-5$ & Grapevine & Akita & C. gloeosporioides & $\mathrm{S}$ & LS & $\mathrm{S}$ \\
\hline $\mathrm{C} 1-8$ & Grapevine & Akita & C. gloeosporioides & $\mathrm{S}$ & LS & $\mathrm{S}$ \\
\hline GC-2 & Grapevine & Akita & C. gloeosporioides & $\mathrm{S}$ & LS & $\mathrm{S}$ \\
\hline B-23 & Grapevine & Akita & C. acutatum & LS & LS & $\mathrm{LS}$ \\
\hline C1-19 & Grapevine & Akita & C. acutatum & LS & LS & LS \\
\hline $\mathrm{C} 1-40$ & Grapevine & Akita & C. acutatum & LS & LS & LS \\
\hline G5-1-7 & Grapevine & Akita & C. acutatum & $\mathrm{LS}$ & $\mathrm{LS}$ & $\mathrm{LS}$ \\
\hline YH1-9 & Grapevine & Akita & C. acutatum & LS & LS & LS \\
\hline FGGC01011 & Grapevine & Fukuoka & C. gloeosporioides & $\mathrm{S}$ & LS & $\mathrm{S}$ \\
\hline FGGC01084 & Grapevine & Fukuoka & C. gloeosporioides & $\mathrm{S}$ & LS & $\mathrm{S}$ \\
\hline FGGC01088 & Grapevine & Fukuoka & C. gloeosporioides & $\mathrm{S}$ & LS & $\mathrm{S}$ \\
\hline FGGC01100 & Grapevine & Fukuoka & C. gloeosporioides & HR & $\mathrm{S}$ & $\mathrm{S}$ \\
\hline FGGC01101 & Grapevine & Fukuoka & C. gloeosporioides & HR & $\mathrm{S}$ & HR \\
\hline S-7 & Apple & Akita & C. gloeosporioides & $\mathrm{S}$ & LS & HR \\
\hline S-12 & Apple & Akita & C. gloeosporioides & $\mathrm{S}$ & LS & HR \\
\hline S-20 & Apple & Akita & C. gloeosporioides & $\mathrm{S}$ & LS & HR \\
\hline $\mathrm{H}-44$ & Apple & Akita & C. acutatum & $\mathrm{LS}$ & LS & LS \\
\hline M-82 & Apple & Akita & C. acutatum & LS & LS & LS \\
\hline $\mathrm{T}-22$ & Apple & Akita & C. acutatum & LS & LS & LS \\
\hline FPeCG-9301 & Peach & Fukuoka & C. acutatum & LS & LS & LS \\
\hline MAFF305138 & Peach & Unknown & C. acutatum & LS & LS & LS \\
\hline MAFF305596 & Loquat & Chiba & C. acutatum & LS & LS & LS \\
\hline GC-P-38 & Prune & Nagano & C. acutatum & LS & LS & LS \\
\hline MAFF410044 & Japanese plum & Nagano & C. acutatum & LS & LS & LS \\
\hline Chestnut-1 & Japanese chestnut & Ibaraki & C. gloeosporioides & $\mathrm{S}$ & LS & IR \\
\hline Chestnut-2 & Japanese chestnut & Ibaraki & C. gloeosporioides & $\mathrm{S}$ & LS & IR \\
\hline GC-M-1 & Japanese chestnut & Nagano & C. acutatum & $\mathrm{S}$ & LS & LS \\
\hline GC-B-1 & Blueberry & Nagano & C. acutatum & LS & LS & LS \\
\hline NM-1 & Strawberry & Tochigi & C. gloeosporioides & $\mathrm{S}$ & LS & IR \\
\hline $\mathrm{Na91-016}$ & Strawberry & Tochigi & C. acutatum & LS & LS & LS \\
\hline AL-5 & Strawberry & Nagasaki & C. acutatum & LS & $\mathrm{LS}$ & LS \\
\hline AL-9 & Strawberry & Nagasaki & C. acutatum & LS & LS & $\mathrm{LS}$ \\
\hline Cf: $5-0$ & Strawberry & Nagasaki & C. gloeosporioides & $\mathrm{S}$ & LS & $\mathrm{S}$ \\
\hline GC-AK-1 & Akebia & Nagano & C. acutatum & LS & LS & LS \\
\hline GC-RP-8 & Acacia & Nagano & C. acutatum & LS & LS & LS \\
\hline 1073R & Tea & Shizuoka & C. gloeosporioides & $\mathrm{S}$ & LS & $\mathrm{S}$ \\
\hline
\end{tabular}

\footnotetext{
a $\mathrm{S}=$ sensitive; $\mathrm{LS}=$ less sensitive; $\mathrm{IR}=$ intermediately resistant; HR = highly resistant; $\mathrm{R}=$ resistant.

${ }^{\mathrm{b}}$ Identified by polymerase chain reaction (PCR) using species-specific primers of CgInt and CaInt 2 .

c Published by Fukaya (15).

d Published by Yano et al. (44).
} 
Cycle sequencing reaction products were purified by ethanol precipitation, and then sequenced using ABI PRISM 3100 automated sequencer (Applied Biosystems).

Molecular phylogenetic analysis of ITS and 5.8S regions of rDNA. The ITS and 5.8S regions of rDNA were amplified. Both forward and reverse nucleotides were sequenced and assembled; once completed the nucleotide bases were aligned using Clustal X v1.8 (40). Further visual alignments were done in Sequence Alignment (Se-Al) Editor v.2.0 (31). The aligned sequences were analyzed together with the out-group sequence of $C$. crassipes (accession no. AJ536230) obtained from GenBank.

Phylogenetic analysis of the aligned sequences was done by distanced parsimony methods. The distance matrix for the aligned sequences was calculated using Kimura's two-parameter method (21) and was analyzed with the neighbor-joining (NJ) method (32). The maximumparsimony analysis was also done. Included in the analysis were positions with gaps as a fifth character since they may be informative for inferring phylogenies. Reliability of the inferred trees was estimated by 1,000 bootstrap resampling using the same program. Parsimony analysis was done by PAUP v4.0b (39) using the heuristic search option with 100 random stepwise-addition sequences to search for the most parsimonious tree. Bootstrap (8) values were generated with 1,000 replicate heuristic searches to estimate support for clade stability of the consensus tree using the same program.

\section{RESULTS}

Response to fungicides. The phenotypic difference of sensitivities to thiophanate-methyl, diethofencarb, and iminoctadine-triacetate are shown in Table 1. Five isolates of $C$. gloeosporioides had $\mathrm{EC}_{50}$ values of $>100 \mathrm{mg} / \mathrm{liter}$ of thiophan- ate-methyl and were grouped as highly resistant (HR), whereas three isolates had $\mathrm{EC}_{50}$ values between 10 and $100 \mathrm{mg} / \mathrm{liter}$ and were classified as intermediately resistant (IR), and 21 isolates with $\mathrm{EC}_{50}$ values $<1 \mathrm{mg} /$ liter were sensitive (S). With respect to diethofencarb, five isolates of $C$. gloeosporioides with an $\mathrm{EC}_{50}$ value of $<1$ $\mathrm{mg} /$ liter were determined to be sensitive (S), and 24 isolates with $\mathrm{EC}_{50}$ values of $>100 \mathrm{mg} /$ liter were considered less sensitive (LS). With iminoctadine-triacetate, seven isolates with $\mathrm{EC}_{50}$ values between 100 and $1,000 \mathrm{mg} /$ liter were highly resistant (HR), three isolates with $\mathrm{EC}_{50}$ values between 10 and $100 \mathrm{mg} /$ liter were intermediately resistant (IR), and 19 isolates with $\mathrm{EC}_{50}$ values of $<1 \mathrm{mg} /$ liter were sensitive (S). On the other hand, C. acutatum isolates were inherently less sensitive to the three fungicides, and the $\mathrm{EC}_{50}$ values for all isolates excluding GC-M-1 were between 1 and $10 \mathrm{mg} /$ liter (thiophanatemethyl), >100 mg/liter (diethofencarb), and between 100 and 1,000 mg/liter (iminoctadine-triacetate).

Species identification by PCR. Using the species-specific primers CgInt and CaInt2, 29 isolates were identified as $C$. gloeosporioides and 22 isolates as $C$. acutatum. The isolates from apple, Japanese pear, grapevine, Japanese chestnut, and strawberry were included in these two species. The isolates from peach, prune, loquat, Japanese plum, akebia, acacia, and blueberry were exclusively $C$. acutatum, whereas the only isolate from tea was $C$. gloeosporioides (Table 1).

Mutation of $\beta$-tubulin gene. Forward and reverse nucleotides of the $\beta$-tubulin gene were sequenced and assembled. These sequences were confirmed using two replicates to ensure accuracy. The mutation at the deduced amino acid codons 198 and 200 in partially amplified $\beta$ tubulin gene obtained from 11 isolates of C. gloeosporioides and 4 isolates of $C$.

Table 2. Mutation and deduced amino acid substitutions in the partial sequence of the $\beta$-tubulin gene in isolates of Colletotrichum spp. with different phenotypic responses to thiophanate-methyl

\begin{tabular}{llclc}
\hline & & & \multicolumn{2}{c}{ Sequence in codon (amino acid) } \\
\cline { 3 - 4 } Isolate & Species & Response $^{\text {a }}$ & $\mathbf{1 9 8}$ & $\mathbf{2 0 0}$ \\
\hline I5-1 $^{\mathrm{b}}$ & C. gloeosporioides & S & GAG (Glu) & TTC (Phe) \\
I9-1 $^{\mathrm{b}}$ & C. gloeosporioides & S & GAG (Glu) & TTC (Phe) \\
M14-2 $^{\mathrm{b}}$ & C. gloeosporioides & IR & GAG (Glu) & TAC (Tyr) \\
M19-1 & C. gloeosporioides & IR & GAG (Glu) & TAC (Tyr) \\
SA02-1-1 & C. gloeosporioides & HR & GCG (Ala) & TTC (Phe) \\
SA02-3-2 & C. gloeosporioides & S & GAG (Glu) & TTC (Phe) \\
SA02-5-1 & C. gloeosporioides & HR & GCG (Ala) & TTC (Phe) \\
SA02-6-1 & C. gloeosporioides & S & GAG (Glu) & TTC (Phe) \\
SA02-8-1 & C. gloeosporioides & HR & GCG (Ala) & TTC (Phe) \\
GC-2 & C. gloeosporioides & S & GAG (Glu) & TTC (Phe) \\
NM-1 & C. gloeosporioides & S & GAG (Glu) & TTC (Phe) \\
GC1-1 & C. acutatum & LS & GAG (Glu) & TTC (Phe) \\
GC1-2 & C. acutatum & LS & GAG (Glu) & TTC (Phe) \\
G5-1-7 & C. acutatum & LS & AAG (Lys) & TTC (Phe) \\
Na91-016 & C. acutatum & LS & AAG (Lys) & TTC (Phe) \\
\hline
\end{tabular}

${ }^{\text {a }} \mathrm{S}=$ sensitive; $\mathrm{IR}=$ intermediately resistant; $\mathrm{HR}$ = highly resistant; $\mathrm{LS}=$ less sensitive.

b Published by Yano et al. (44).

c Published by Ishii (17). acutatum are shown in Table 2. Three isolates of $C$. gloeosporioides, SA02-1-1, SA02-5-1, and SA02-8-1, highly resistant to thiophanate-methyl, showed a point mutation from GAG to GCG at codon 198 , resulting in substitution of Glu with Ala. However, the sequences of codon 198 were GAG (Glu) in intermediately thiophanatemethyl resistant and sensitive isolates. The sequence at codon 200 for intermediately resistant isolates of $C$. gloeosporioides, M14-2 and M19-1 derived from Japanese pear, possessed the change from TTC (Phe) to TAC (Tyr). In C. acutatum, two isolates, G5-1-7 and Na91-016, showed less sensitivity to thiophanate-methyl and had the sequences of AAG (Lys) at codon 198. On the other hand, two other isolates, GC1-1 and GC1-2, had the wild type sequences of GAG (Glu) and TTC (Phe) at codons 198 and 200, respectively.

Phylogenetic analysis inferred from ITS and 5.8S rDNA sequence. For molecular phylogenetic analysis, 572 to 585 base pairs of the ITS and 5.8S rDNA regions were analyzed. Of the 615 total characters including gaps, 543 characters were constant and 15 variable characters were parsimony-uninformative. Moreover, 57 characters were parsimony-informative and gaps were treated as missing. In a neighbor-joining tree constructed from the ITS and 5.8S rDNA sequences, C. gloeosporioides isolates fell into one major clade and C. acutatum isolates fell into two major clades with 100,97 , and $83 \%$ bootstrap support, respectively (Fig. 1). The ITS and 5.8S rDNA phylogram had a consistency index (CI) of 0.927 , a retention index (RI) of 0.994 , retention consistency (RC) of 0.922 , and a tree length of 82. In a maximum-parsimony tree constructed from the ITS and 5.8S rDNA sequences, results were similar to those obtained from neighbor-joining analysis: $C$. gloeosporioides isolates fell into one major clade, and $C$. acutatum isolates fell into two major clades with 100,90 , and $77 \%$ bootstrap support, respectively (Fig. 2). The ITS and 5.8S rDNA phylogram had a CI of 0.767 , a RI of 0.977 , RC of 0.749 , and a tree length of 103 . The $C$. acutatum isolates showed higher sequence divergence on ITS2 region $(4.4 \%)$ than the ITS1 region $(2.7 \%)$, whereas no sequence divergence on 5.8S rDNA region was observed. Similarly, C. gloeosporioides isolates showed higher sequence divergence in the ITS2 region $(3.2 \%)$ than in the ITS1 regions $(2.9 \%)$, and no sequence divergence in the $5.8 \mathrm{~S}$ rDNA region was recognized.

\section{DISCUSSION}

C. gloeosporioides isolates from various fruit trees and other hosts in Japan showed different sensitivity to thiophanate-methyl, diethofencarb, and iminoctadine-triacetate, whereas all $C$. acutatum isolates were inherently less sensitive to the three fungicides. Benzimidazole resis- 
tance in C. gloeosporioides and lower sensitivity to both benzimidazoles and diethofencarb in $C$. acutatum have been reported by several researchers in Japan $(13,15,17,18,33,44)$.

In this study, most of the C. gloeosporioides isolates tested were still sensitive to thiophanate-methyl and iminoctadine-triacetate. Thiophanate-methylresistant isolates were obtained from Japanese pear and grapevine. However, thiophanate-methyl-resistant isolates were also detected from apple before $(18,33)$. According to our results, isolates of C. gloeosporioides were classified into three groups: sensitive, intermediately resistant, and highly resistant to thiophanate-methyl. Highly thiophanate-methyl-resistant isolates of $C$. gloeosporioides showed negative cross-resistance to diethofencarb as previously reported $(18,33,44)$. On the other hand, isolates of $C$. gloeosporioides with intermediate resistance to thiophanate-methyl were found only in Japanese pear orchards in Kochi Prefecture, Japan, and they did not show negative crossresistance to diethofencarb as reported by Yano et al. (44). Sato et al. (33) reported that $C$. gloeosporioides could be distinguished from $C$. acutatum based on sensitivity to benomyl and diethofencarb. However, the difference in sensitivity to benzimidazole fungicides and diethofencarb cannot always be used to distinguish the two Colletotrichum species because we found some isolates of C. gloeosporioides

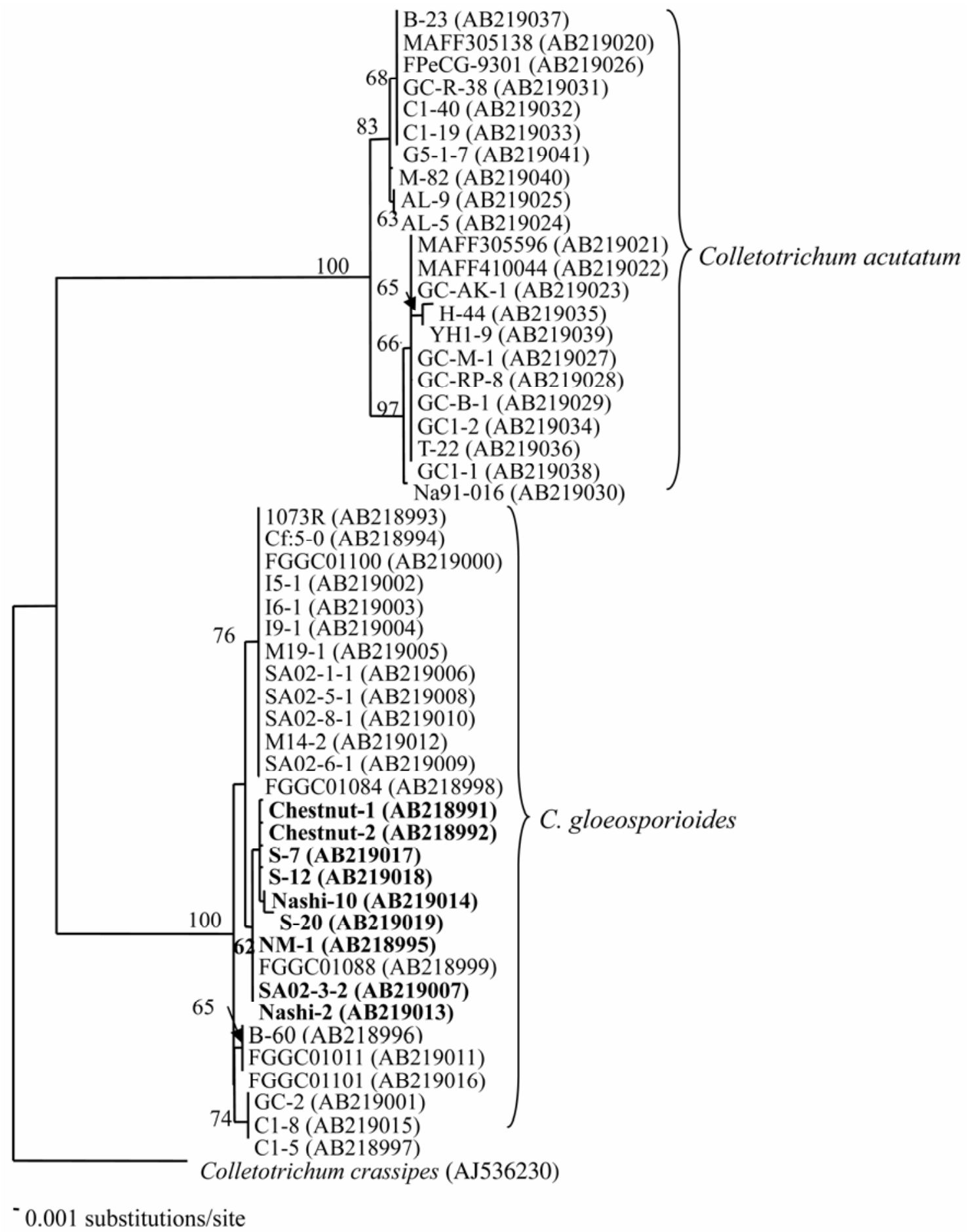

Fig. 1. Internal transcribed spacer (ITS) and 5.8S sequence-based tree generated using neighbor-joining analysis. Numbers at the branch node indicate the confidence values from bootstrap analysis using 1,000 replications. Bootstrap values above $60 \%$ are presented. Colletotrichum gloeosporioides isolates in bold type were resistant to iminoctadine-triacetate. Number in parentheses is accession number in GenBank. 
with fungicide sensitivity similar to that of C. acutatum.

Although Fukaya (13) found that the dormant spray of iminoctadine-triacetate was effective in controlling grapevine ripe rot caused by $C$. gloeosporioides and $C$. acutatum in vineyards, isolates of the two species less sensitive to this fungicide have been detected from grapevine and apple (14). Moreover, iminoctadine-triacetate-resistant isolates of C. gloeosporioides were also found from Japanese pear, strawberry, and Japanese chestnut in this study. This suggests that iminoctadine-triacetate-resistant C. gloeosporioides isolates may be distributed widely in various fruit crops in Japan.
Several researchers have reported that high resistance or intermediate resistance to benzimidazole fungicides was caused by a single point mutation at codon 198 or 200 of $\beta$-tubulin in filamentous fungi $(1,17,22,28,44)$. In the present study, the partial sequence of the $\beta$-tubulin gene of C. gloeosporioides isolates highly resistant to thiophanate-methyl also had the amino acid substitution of Glu (GAG) with Ala (GCG) at codon 198. In intermediately resistant isolates of C. gloeosporioides, Phe (TTC) was substituted with Tyr (TAC) at codon 200. On the other hand, the sequence in $C$. acutatum isolates was GAG or AAG at codon 198. The isolates of $C$. acutatum used for this study showed the same sequence at codon 200 as C. gloeosporioides. Also in our study, the amino acid substitution of glutamic acid (wild type) with lysine was confirmed to codon 198 in C. acutatum. Albertini et al. (1) reported that codon 198, which encodes glutamic acid in benzimidazole-sensitive strains, could convert to a codon for alanine, glycine, lysine, or glutamine in benzimidazole-resistant strains. However, glutamic acid was replaced by alanine, glycine, lysine, or glutamine in two isolates of C. acutatum, GC1-1 and GC1-2, obtained from Japanese pear. Peres et al. (29) mentioned that isolates of $\mathrm{C}$. $\mathrm{acu}$ -

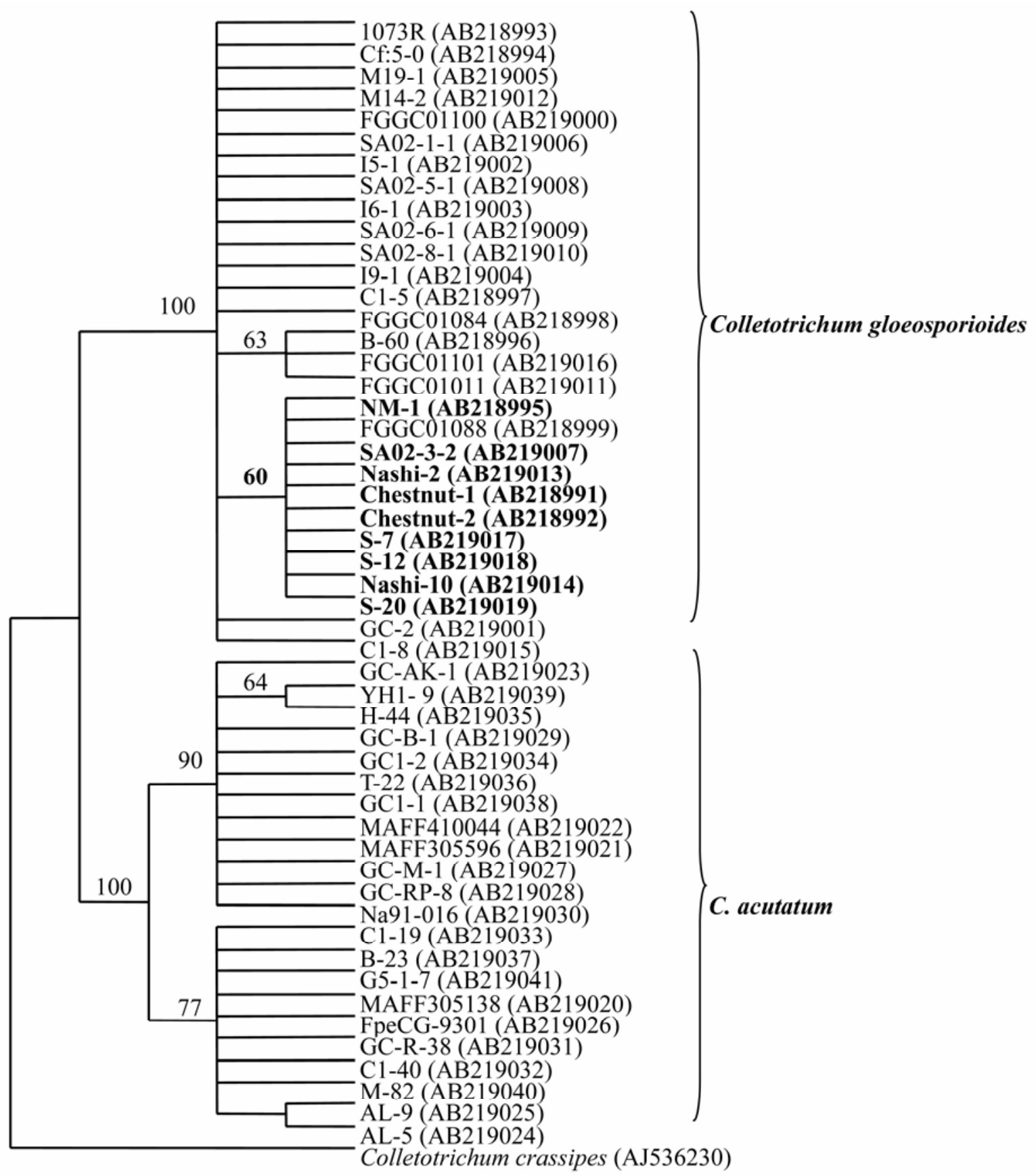

Fig. 2. Internal transcribed spacer (ITS) and 5.8S sequence-based tree generated using maximum-parsimony analysis. Numbers at the branch node indicate the confidence values from bootstrap analysis using 1,000 replications. Bootstrap values above $60 \%$ are presented. Colletotrichum gloeosporioides isolates in bold type were resistant to iminoctadine-triacetate. Number in parentheses is accession number in GenBank. 
tatum were neither highly sensitive nor highly tolerant to benomyl. This suggests that less sensitivity to thiophanate-methyl found in two isolates may be governed by other factors. De Waard (6) and Del Sorbo et al. (7) reported that ATP binding cassette $(\mathrm{ABC})$ transporter systems can play a role in multidrug resistance in filamentous fungi. Thus, factors other than the mutation of the $\beta$-tubulin gene, such as transporter systems, might play a role in less sensitivity to benzimidazoles in cells of $C$. acutatum.

The molecular phylogenetic analysis showed that the $C$. gloeosporioides and $C$. acutatum are distinct species based on the nucleotide sequence of ITS and 5.8S rDNA regions, and the result corresponds with the species-specific PCR primer reaction. According to Moriwaki et al. (25), $C$. gloeosporioides isolates obtained from various host plants could be separated into three groups based on the sequence of the ITS1 region, and isolates from fruit crops were in the same ITS group. Our results also showed that the ITS1 sequence divergence of $C$. gloeosporioides isolates from various fruit crops was low. Freeman (10) and Correll et al. (5) used random amplified polymorphic DNA and restriction fragment length polymorphism analyses to group the Colletotrichum species from different geographic regions and host plants; however, the sequence divergence of ITS and 5.8S rDNA regions did not correspond with geographical differences, host specificity, and fungicide sensitivity in our study. Although nine of 10 C. gloeosporioides isolates showing resistance to iminoctadine-triacetate fell into the same subgroup, there was no significant relationship between the ITS and 5.8S rDNA sequence and sensitivity to iminoctadinetriacetate. Additional isolates resistant to this fungicide should be analyzed in the future.

C. acutatum isolates separated into two distinct ITS groups, and the differentiation was supported by a highly reliable bootstrap value. Moriwaki et al. (25) reported that $C$. acutatum isolates obtained from various host plants did not show significant divergence in the ITS1 sequence and belonged to one ITS group. Similarly, our sequence data of $C$. acutatum isolates obtained from various fruit crops also showed low divergence in the ITS1 region. However, the sequence data of the ITS2 region within $C$. acutatum isolates showed higher divergence than the ITS1 region, and sequence variation of the ITS2 region might relate to intraspecies differences in C. acutatum. Sreenivasaprasad et al. (36) suggested that ITS1 sequence variation was useful in explaining the phylogenetic relationship within Colletotrichum. However, Sherriff et al. (34) and Freeman et al. (11) considered the ITS2 sequence too highly variable to be useful in intraspecies differentiation. Similarly, O'Donnell and
Cigelnik (27) reported that divergence of the ITS2 sequence of Fusarium species was discordant with the species phylogeny inferred from three unlinked loci. In our opinion, divergence of ITS2 sequence in $C$. acutatum isolates obtained from various fruit crops in Japan might not correspond to species difference but might correspond with intraspecies differences. Recently, Peres et al. (29) mentioned that $\mathrm{C}$. $a c u$ tatum is a group species and the relationships among populations correspond to different host plants and infection strategies. Intraspecies were recognized to exist in Colletotrichum species, especially in isolates that possess differences in pathogenicity $(3,5,10,34)$. Although ITS and 5.8S rDNA sequences did not show any phylogenetic relationship to geography, host plant, and fungicide sensitivity, the results suggest that a subspecies might exist in $C$. acutatum obtained from various fruit crops in Japan.

\section{ACKNOWLEDGMENTS}

Several isolates of $C$. gloeosporioides and $C$. acutatum examined in this study were supplied from the National Institute of Agrobiological Sciences, Tochigi Agricultural Center, National Institute of Vegetable and Tea Science, Aichi-ken Agricultural Research Center, Ibaraki Agricultural Center, Nagano Fruit Tree Experiment Station, Shizuoka Tea Experiment Station, and by M. Yamaguchi, Saga Prefecture, for which we are grateful. We thank Nobuyo Koike for the technical assistance. We also sincerely thank Saligrama A. Deepak, National Institute for Agro-Environmental Sciences, Japan, for critical reading of the manuscript. The $N$-phenylcarbamate fungicide diethofencarb was kindly supplied by Sumitomo Chemical Co. Ltd., Japan.

\section{LITERATURE CITED}

1. Albertini, C., Gredt, M., and Leroux, P. 1999. Mutations of the $\beta$-tubulin gene associated with different phenotypes of benzimidazole resistance in the cereal eyespot fungi Tapesia yallundae and Tapesia acuformis. Pestic. Biochem. Physiol. 64:17-31.

2. Bernstein, B., Zehr, E. I., Dean, R. A., and Shabi, E. 1995. Characteristics of Colletotrichum from peach, apple, pecan, and other hosts. Plant Dis. 79:478-482.

3. Cannon, P. F., Bridge, P. D., and Monte, E. 2000. Linking the past, present, and future of Colletotrichum systematics. Pages 1-20 in: Host Specificity, Pathology, and HostPathogen Interactions of Colletotrichum. D. Prusky, S. Freeman, and M. B. Dickman, eds. American Phytopathological Society, St. Paul, $\mathrm{MN}$.

4. Chung, W.-H., and Tsukiboshi, T. 2005. A new species of Curvularia from Japan. Mycotaxon 91:49-54.

5. Correll, J. C., Guerber, J. C., Wasilwa, L. A., Sherrill, J. F., and Morelock, T. E. 2000. Interand intra-species variation in Colletotrichum and mechanisms which affect population structure. Pages 145-179 in: Host Specificity, $\mathrm{Pa}-$ thology, and Host-Pathogen Interactions of Colletotrichum. D. Prusky, S. Freeman, and M. B. Dickman, eds. American Phytopathological Society, St. Paul, MN.

6. De Waard, M. A. 1997. Significance of ABC transporters in fungicide sensitivity and resistance. Pestic. Sci. 51:271-275.

7. Del Sorbo, G., Andrade, A. C., Van Nistelrooy, J. A. L., Balzi, E., and De Waard, M. A. 1997. Multidrug resistance in Aspergillus nidulans involves novel ATP-binding cassette transporters. Mol. Gen. Genet. 254:417-426.

8. Felsenstein, J. 1985. Confidence limits on phylogenies: An approach using the bootstrap. Evolution 39:783-791.

9. Förster, H., and Adaskaveg, J. E. 1999. Identification of subpopulations of Colletotrichum acutatum and epidemiology of almond anthracnose in California. Phytopathology 89:1056-1065.

10. Freeman, S. 2000. Genetic diversity and host specificity of Colletotrichum species on various fruits. Pages 131-144 in: Host Specificity, Pathology, and Host-Pathogen Interactions of Colletotrichum. D. Prusky, S. Freeman, and M. B. Dickman, eds. American Phytopathological Society, St. Paul, MN.

11. Freeman, S., Minz, D., Maymon, M., and Zveibil, A. 2001. Genetic diversity within Colletotrichum acutatum sensu Simmonds. Phytopathology 91:586-592.

12. Freeman, S., and Shabi, E. 1996. Crossinfection of subtropical and temperate fruits by Colletotrichum species from various hosts. Physiol. Mol. Plant Pathol. 49:395-404.

13. Fukaya, M. 2001. Control of grapevine ripe rot and fluctuation of fungicide sensitivity of the pathogen. Abstr. 11th Sympos. Res. Comm. Fungic. Resistance, Phytopathol. Soc. Jpn.: 9 15 (In Japanese with English summary).

14. Fukaya, M. 2002. Different sensitivity to iminoctadine-triacetate in two fungal pathogens of grape ripe rot. Jpn. J. Phytopathol. 68:263-264 (Japanese abstr.).

15. Fukaya, M. 2004. First report of Japanese pear anthracnose disease caused by Colletotrichum acutatum and its chemical control. Jpn. J. Phytopathol. 70:184-189 (In Japanese with English abstr.).

16. Goodwin, D. C., and Lee, S. B. 1993. Microwave miniprep of total genomic DNA from fungi, plants, protists and animals for PCR. Biotechniques 15:438-444.

17. Ishii, H. 2002. DNA-based approaches for diagnosis of fungicide resistance. Pages 242259 in: Agrochemical Resistance: Extent, Mechanism, and Detection. J. M. Clark and I. Yamaguchi, eds. American Chemical Society, Washington, DC.

18. Ishii, H., Iwamoto, S., Nishimura, K., and Fukaya, M. 1998. Comparative studies on fungicide sensitivity and other characteristics in Colletotrichum isolated from various plant species. Proc. 1998 Brighton Conf. - Pests Dis., 529-534.

19. Jeffries, P., Dodd, J. C., Jeger, M. J., and Plumbley, R. A. 1990. The biology and control of Colletotrichum species on tropical fruit. Plant Pathol. 39:343-366.

20. Johnston, P. P., and Jones, D. 1997. Relationships among Colletotrichum isolates from fruit-rots assessed using rDNA sequences. Mycologia 89:420-430.

21. Kimura, M. 1980. A simple method for estimating evolutionary rate of base substitutions through comparative studies of nucleotide sequences. J. Mol. Evol. 16:111-120.

22. Koenraadt, H., Somerville, S. C., and Jones, A. L. 1992. Characterization of mutations in the beta-tubulin gene of benomyl-resistant field strains of Venturia inaequalis and other plant pathogenic fungi. Phytopathology 82:13481354.

23. Martínez-Culebras, P. V., Querol, A., SuarezFernandez, M. B., Garcla-Lopez, M. D., and Barrio, E. 2003. Phylogenetic relationships among Colletotrichum pathogens of strawberry and design of PCR primer for their identification. J. Phytopathol. 151:135-143.

24. Mills, P. R., Sreenivasaprasad, S., and Brown, A. E. 1992. Detection and differentiation of Colletotrichum gloeosporioides isolates using PCR. FEMS Microbiol. Lett. 98:137-144.

25. Moriwaki, J., Tsukiboshi, T., and Sato, T. 
2002. Grouping of Colletotrichum species in Japan based on rDNA sequences. Jpn. J. Gen. Plant Pathol. 68:307-320.

26. O'Donnell, K. 1993. Fusarium and its near relatives. Pages 225-236 in: The Fungal Holomorph: Mitotic, Meiotic, and Pleomorphic Speciation in Fungal Systematics. D. R. Reynolds and J. W. Taylor, eds. CAB International, Wallingford, UK.

27. O'Donnell, K., and Cigelnik, E. 1996. Two divergent intragenomic rDNA ITS2 types within a monophyletic lineage of the fungus Fusarium are nonorthologous. Mol. Phylogenet. Evol. 7:103-116.

28. Peres, N. A. R., Souza, N. L., Peever, T. L., and Timmer, L. W. 2004. Benomyl sensitivity of isolates of Colletotrichum acutatum and $C$. gloeosporioides from citrus. Plant Dis. 88: 125-130.

29. Peres, N. A. R., Timmer, L. W., Adaskaveg, J. E., and Correll, J. C. 2005. Lifestyles of Colletotrichum acutatum. Plant Dis. 89:784-796.

30. Prior, C., Elango, F., and Whitwell, A. 1992. Chemical control of Colletotrichum infection in mangoes. Pages 326-336 in: ColletotrichumBiology, Pathology, and Control. J. A. Bailey and M. J. Jeger, eds. CAB International, Wallingford, UK.

31. Rambaut, A. 2000. Se-Al: Sequence alignment editor. Department of Zoology, University of Oxford, Oxford, UK

32. Saitou, N., and Nei, M. 1987. The neighborjoining method: A new method for reconstructing phylogenetic trees. Mol. Biol. Evol. 4:406-425.

33. Sato, T., Uematsu, S., Iijima, A., and Ko- ganezawa, H. 1998. Occurrence of apple bitter rot by grayish colony form of Colletotrichum acutatum in Japan and pathogenicity to apple fruits of C. acutatum and Glomerella cingulata isolated from other plants. Nippon Kingakukai Kaiho 39:35-44 (In Japanese with English abstr.).

34. Sherriff, C., Whelan, M. J., Arnold, G. M., Lafay, J.-F., Brygoo, Y., and Bailey, J. A. 1994 Ribosomal DNA sequence analysis reveals new species groupings in the genus Colletotrichum. Exp. Mycol. 18:121-138.

35. Sreenivasaprasad, S., Mills, P. R., and Brown, A. E. 1994. Nucleotide sequence of the rDNA spacer 1 enables identification of isolates of Colletotrichum as C. acutatum. Mycol. Res. 98:186-188.

36. Sreenivasaprasad, S., Mills, P. R., Meehan, B. M., and Brown, A. E. 1996. Phylogeny and systematics of 18 Colletotrichum species based on ribosomal DNA spacer sequences. Genome 39:499-512.

37. Sreenivasaprasad, S., Sharda, K., Brown, A. E., and Mills, P. R. 1996. PCR-based detection of Colletotrichum acutatum on strawberry. Plant Pathol. 45:650-655.

38. Sutton, B. C. 1992. The genus Glomerella and its anamorph Colletotrichum. Pages 1-26 in: Colletotrichum-Biology, Pathology, and Control. J. A. Bailey and M. J. Jeger, eds. CAB International, Wallingford, UK.

39. Swofford, D. L. 2000. PAUP*. Phylogenetic Analysis Using Parsimony (* and other methods). Version 4. Sinauer Associates, Sunderland, MA.
40. Thompson, J. D., Gibson, T. J., Plewniak, F Jeanmougin, F., and Higgins, D. G. 1997. The Clustal X windows interface: Flexible strategies for multiple sequence alignment aided by quality analysis tools. Nucleic Acids Res. 25:4876-4882.

41. The Phytopathological Society of Japan. 2000 Common Names of Plant Diseases in Japan. Japan Plant Protection Association, Tokyo, Japan. p. 880

42. Wallen, J. M. 1992. Colletotrichum diseases of perennial and other cash crops. Pages 167-185 in: Colletotrichum-Biology, Pathology, and Control. J. A. Bailey and M. J. Jeger, eds. CAB International, Wallingford, UK.

43. White, T. J., Bruns, T., Lee, S. B., and Taylor, J. 1990. Amplification and direct sequencing of fungal ribosomal RNA genes for phylogenetics. Pages 315-322 in: PCR Protocols: A Guide to Methods and Applications. M. Gelfand, D. Sninsky, and T. White, eds. Academic Press, San Diego, CA

44. Yano, K., Ishii, H., Fukaya, M., Kawada, Y, and Sato, T. 2004. Anthracnose on Japanese pear caused by intermediately benzimidazoleresistant strains of Colletotrichum gloeosporioides (Glomerella cingulata). Jpn. J. Phytopathol. 70:314-319 (In Japanese with English abstr.).

45. Yarden, O., and Katan, T. 1993. Mutations leading to substitutions at amino acids 198 and 200 of beta-tubulin that correlate with benomyl-resistance phenotypes of field strains of Botrytis cinerea. Phytopathology 83:14781483. 